\title{
Professional Demand of Objectivity and Its Effect on Media Objectivity in Conflict Management in Journalism
}

\author{
Israel W. Udomisor ${ }^{1}$, Anthony Paul Udoh ${ }^{2}$ \\ ${ }^{1}$ The Department of Mass Communication, University of Maiduguri, Maiduguri, Nigeria \\ ${ }^{2}$ The Department of Communication Art, University of Uyo, Uyo, Nigeria \\ Email: iriswilson2012@yahoo.com
}

Received 15 January 2015; accepted 7 February 2015; published 11 February 2015

Copyright (C) 2015 by authors and Scientific Research Publishing Inc.

This work is licensed under the Creative Commons Attribution International License (CC BY). http://creativecommons.org/licenses/by/4.0/

\section{Abstract}

The mass media or the press occupies a central position in the society. It is basically involved in the information, education, and entertainment as well as cultural transmission. The enormity of the functions of the press makes it imperative for a guiding principles or code of ethics which includes objectivity. However, current practices in the media especially as pertains to conflict management negate this ethical standard or code, hence the imperative of this study which seeks to investigate how the media can engage in conflict management without breaching this cherished and longstanding principle. This study is based on the framing analysis theory and the agenda setting theory of communication. Using the documentary or historical survey method in the collection of data, it is observed that the media are naturally attracted to conflict and some journalists or media organisation use their position to fight individual or group battle while others blow some seemingly innocuous issues out of proportion thereby generating conflict in the society. It is also noted that the media sometimes play down, frame or slant some facts to avoid escalation of conflict. All these negate the principle of objectivity. It is therefore recommended that the media should at all times value, uphold and apply objectivity in all its reportage, by separating facts from comments, for effective conflict management. The media should also embrace proactive conflict management approach, peace journalism, investigative journalism and agenda setting for peaceful resolution of conflicts.

\section{Keywords}

Objectivity, Professionalism, Conflict, Management 


\section{Introduction}

In recent past, there have been serious controversies over the practice of the mass media vis-a-vis adherence to ethical codes of the profession. These controversies have made many, both within and without the media circle, to lose confidence as well as have serious doubt on the mass media. The credibility which was earlier enjoyed by the media inspired early communication theorists to assume the position that the mass media are capable of creating a very powerful effect on the audience compared to that of a bullet released from a gun-the magic bullet theory. However, with an increasing media literacy coupled with the understanding that some of the media activities are nothing but make belief with the tendency of conferring undeserved status on some members of the society, the audience members became more selective in terms of exposure, attention, perception and retention. Moreover, some attempts by communication scholars to restore the media image by enhancing the credibility through enforcement of the media ethics, especially as pertains to objectivity, have become more challenged due to current demands of the media in conflict management, hence the imperative of this study to assess how the media can maintain objectivity while at the same time involving in conflict management both within the media industry and in the larger society.

\section{Media Objectivity}

Journalism is a discipline of collecting, analysing, verifying, and presenting news regarding current events, trends, issues and people, (Hasan, 2013). Mcquail cited in Hasan defines journalism as paid writing for public media with reference to actual and on-going events of public interest. It is a term used both in the print and electronic media as both are involved in the collection or gathering, analysing, verifying and the presentation to the public through the newspapers, magazine, radio, television, and the internet among others.

It has been seen to wield so much influence in the social system. It could engender unity, peace and development as well as create serious security threat, conflict, crisis and other undesirable situation in the society. This explains why some communication scholars regard journalism or mass communication as a double edge sword having the ability to construct and or destroy, make and or mar a social system. In collaboration, Baran (2004) notes that since almost all conflict involve communication problem, the medium, style or attitude of the communicator, plays a sensitive role in either escalating or managing the conflict.

\subsection{Conflict}

Chamberlin is a renowned pastor in one of the Pentecostal churches in South-South Nigeria. Although he was not a born again Christian from birth, childhood or in his youthful age, he became such a devout Christian in the later part of his life both in teaching and dealings. Married with four children evenly segmented in terms of sex, Chamberlin trained his children in a godly way predictive of his calibre. A civil servant though, but he created ample time for his flock and derived joy in the happiness of others either due to vocation, temperament or both. His status in the society in terms of wealth measured in landed property, estates or bank account balance has never bothered him or deters his philanthropic disposition.

However, Chamberlin's wife, Stella, who probably is the reveres of Chamberlin's disposition enjoyed accumulation of wealth and superlatively exhibited the psychological id. Stella wanted to have an estate, a fleet of cars having different colours to match her dresses, manicure and pedicure. She wanted to have a holiday in Palm Island and medical checks in Germany, India, or Saudi Arabia. Sadly though, but Chamberlin's disposition made her dreams a perpetual foetus and this did not get down well with Stella, hence conflict was an unseen but unavoidable resident of their home.

The above sad experience of Chamberlin, probably informs Elliot, Timothy, and Robin's (2004) position which holds that people have incompatible goals placing them in conflict with each other. This can be true of two groups, such as romantic partners who disagree about who should clean the kitchen, or two groups such as a labour union and company management who disagree over wages and working conditions.

Freud in Elliot et al. (2004) argues that conflict is an inevitable by-product of civilization because the goals and needs of individuals often clash with the goals and needs of their fellow human beings.

Every human being has a peculiar perception of certain phenomenon formed through socialization, experiences, etc. Therefore, exposure to stimuli that is at variance with an individual's perception creates disequilibrium-CONFLICT. 
Simply put, conflict is a perceptual incompatibility. To Owens-Ibie (2002), conflict is a product of life and living while Ibrahim (2002) says that conflict is a state of disagreement or argument between people, groups, or countries. Udomisor (2002) views conflict as the by-product of plurality in a free environment which allows opinions and feelings to be fully and freely expressed. This definition seems to situate conflict in a democratic environment probably oblivion of conflicts and even crises which often take place within other systems of government.

For instance, the military era in Nigeria witnessed series of conflicts some of which claimed lives and properties. The Buhari's junta experienced lots of conflicts especially with the press due to his attempt to trim down the tentacles of the media. Ofor (2004) noted that on the assumption of office, Buhari enacted the Decree No. 4 (DN4) of 1984 which was entitled, "Public Officers Protection against False Accusation." This decree was later used to sentence the duo of Tunde Thompson and NdukaIrabor of Guardian Newspaper to one year jail term and their newspaper fined N50000 for being nuisance to the government.

The Babangida's junta was not an exemption to this conflict which resulted in the grotesque murder of a veteran journalist, Mr. Dele Giwa, the first Editor-in-Chief of News Watch magazine. Although there are quite a number of them within and outside the country, these are just a few instances within Nigeria.

In a more holistic approach, Udomisor (2002: p. 87) defines conflict as "the result of differences in opinion, attitude and behaviour, differences in philosophical, psychological, sociological, political and economic orientation of interactors in a given system”.

\subsection{Statement of the Problem}

Journalism is a profession which is guided by some legal and ethical codes. These codes direct the practice of journalists and enabled them to distinguish between right and wrong, good and bad actions. Hasan (2013), states that the code of ethics is an attempt to achieve a just balance between freedom and responsibility. He listed some of the ethical codes of journalism to include: objectivity, accuracy, truthfulness or the non-misrepresentation of facts. Contrarily, the concept of management entails the controlling of the media content to prevent or resolve a conflict and this suggests or implies subjectivity. Also there is an assumption that conflict management practices by the mass media negate the cherished and long standing journalistic ethics—objectivity.

Therefore, media objectivity and the expectation of the media to involve in conflict management are conflicting hence the imperative of this study.

\subsection{Objective of the Study}

The objectives of this study are basically to:

- To assess the possibility of media objectivity.

- To assess media approach to conflict management.

- To examine how journalist can adhere to this ethical demand of objectivity while engaging in conflict management.

\subsection{Research Questions}

In order to achieve the objective(s) of this study, the following questions were asked:

- Is there media objectivity.

- How do the media manage conflict.

- How can the media mange conflict in the face of objectivity principle?

\subsection{Theoretical Framework}

This study is rooted in the framing and the agenda setting theory of communication due to their relationship and explanation of the concept of the concept of study.

Framing theory or frame analysis theory as developed by Goffman is micro-level theory focussing on how individuals learn to routinely make sense of their social world. According to Baran and Davis (2009), the theory implies that journalism's role should be to provide a forum in which ideas about a social world are routinely presented and debated. "As it is now, this forum is dominated by social institutions having the power to influence frames routinely used to structure news coverage of the social world. These institutions are able to promote 
frames that serve to reinforce or consolidate an existing social order and to marginalise frames that raise questions about or challenge the way things are.” The duo noted that the practice of frame was startlingly evident in internal marine memos that surfaced during the 2007 murder and dereliction of duty trials of men involved in the 2005 killing of twenty-four Iraqi men, women, and children in Haditha. In response to a series of questions posed by Time reporter Tim McGirk as he worked to confirm the official account that the deaths "occurred during combat and were justified, if regrettable," the commanding officers of the unit involved met and developed "Talking Points" designed to shape McGirk's account. One common tactic used by reporters is to spin a story in such a way that it is easily recognised and remembered.

Also, the agenda setting theory, according to Baran and Davis (2009), holds that the media may not be successful much of the time in telling the people what to think, but it is stunningly successful in telling its readers what to think about. This largely implies that the media publication on war, killings, destruction of property and other similar activities by a particular section of a country or state would form the discussion and action of the people in the larger society. If emphasis was on war, then the society would base their comments and opinions on war and if the media lay emphasis on peace, the societal opinion would follow thus.

\section{Media Objectivity and the Demand of Conflict Management in Journalism}

Media is the simple plural of medium which relates to the vehicle, means and institutions for publishing and broadcasting information. The media is a world of its own which is peopled by professionals schooled in the different areas of the field. These professionals who make up this world must be guided by some codes of conduct (ethics) which according to Ernest Greenwood is one of the qualities which an occupation must possess before it is termed a profession.

Hasan (2013), states that the code of ethics is an attempt to achieve a just balance between freedom and responsibility. He listed some of the media ethics to include objectivity, accuracy, truthfulness or the non-misrepresentation of facts.

Objectivity means that the reporter tries to transmit the news untainted by conscious bias and without personal comment or coloration (Dominick, 2011). Corroborating Dominick’s view, Hasan (2013: p. 183) notes that the term which has become frequently held to be essential to journalistic professionalism was not applied to journalistic work until the $20^{\text {th }}$ century, saying that the concept of objectivity has always been somewhat ambiguous, and both journalists and the public tend to identify objectivity in its absence. "The belief in objectivity is a faith in fact. It means that journalists should have something like a neutral point of view, not taking a stand on any issues on which there is some disagreement. Instead, journalists are simply to report what 'both sides' of an issue told them.”

The 1998 codes of ethics for journalists provides for accuracy and fairness which explains that the public has a right to know and that factual, accurate, balanced and fair reporting is the ultimate objective of good journalism. Dominick (2011: p. 403) states, "the journalist's primary loyalty is to the audience to report fully the fact of a story." Similarly, McQuail (2005: p. 200) highlights three features of objective journalism. One is that it adopts a position of neutrality towards the object of reporting," secondly, there is a lack of partisanship, which he explains as not taking sides in matters of dispute or showing bias. Thirdly, objectivity requires strict attachment to accuracy and truth.

Hasan emphasized that the facts of the news must be presented as they are as any deletion or interpretation on the part of the news writer will tend to make the presentation of facts in favour or against a person or any organisation.

In contrast, conflict management entails the collating, coordinating, controlling, and shaping certain facts, materials and resources to prevent the escalation of conflict as well as resolving existing ones. Akpan (2005) noted that conflict management involves efforts or strategies aimed at resolving an already existing conflict. It is a process of handling conflict, to avoid conflict escalation.

In discussing the role of the media in conflict management, John Langlois cited in YII \& Parajon (2007) framed the discussion within four parameters. He firstly, asked how the media contribute to or dampens potential conflict situation, and whether the media play a role in setting agenda for potential third party interveners. The group was also asked to ponder the differences between local media and the international media in reporting on conflict events. They noted that the group was prompted to think about the degree to which media are not root cause of conflict itself. 
"International media sources such as the BBC, CNN, al Arabiya, and al Jazeera have global reach, and as such have an 'agenda setting effect.' This effect, as Steven Livingston explained, revolves around the ideological components of political disagreements, and more specifically the way key actors in conflict seek to manipulate public perceptions of the disagreement. That is actors in any conflict will seek to either minimise or exaggerate the conflict, depending upon their relative position of power. Weak actors will want to 'socialise' the conflict - that is, to enlist allies in their cause against a greater power and to increase the perception of suffering. Actors in positions of dominance seek to 'privatise' the conflict and limit attention to or awareness of the conflict. Those who are weak will seek to draw media coverage to the conflict while those who have power will seek to minimise the extent of the problems," (Ibid).

They are of the view that whereas international media giants are juggernauts in the policy-setting arena, local media play a different role in conflict prevention. Often, local media can contribute to peace merely by restoring levels of trust and self-worth in a population on the brink of or emerging form of violence. George Papagiannis' work in Chad speaks of the ability of the local media to give voice to those who were previously silenced by conflict. Papagiannis shared his impression of running radio stations in refugee camps in Chad. "Genocide is about silencing a people. So when you give someone a microphone and ask them to tell you something, it is like giving something back.”

Papagiannis showed the value of the media in building community, Kemal Kurspahic drew upon his experience in the Balkans to emphasise that the media can just as easily have a deleterious effect and cause an escalation of violence and hate speech. According to Kurspahic account, the media's action in the Balkans is a prime example of how the media can be a source of antagonism and an instigator of conflict rather than a source for peace. Each side (Serbian and Croatian) propagated an "us versus them" mentality among their respective populations to a point of inventing crimes in addition to fanning the flames of ethnic tensions, the media was also guilty of obstructing peace-making efforts by failing to objectively present views of the minority.

YII and Parajon (2007) noted that the media can give voice to those who are advocating tolerance, peace, and negotiation. In Belgrade, those who opposed the war were signalled out as traitors. Had their voices been heard, others might have been inspired to non-violent means of resistance and channels for negotiation could have opened before violence ensued.

Although conflict is seen by many scholars as majorly, a disagreement resulting from a breach in communication, it is also worthy of note that the way and manner as well as the content of certain communicated information could trigger conflicts in a society. For instance, the 2002 newspaper comment involving the Islamic Prophet Muhammad which sparked major religious riots and caused a fatwa to be issued on the author, Isioma Nkemdilim Nkiruka Daniel.

On November 16, 2002, Isioma wrote a piece on Miss World beauty pageant that was to be held in Nigeria later that year. Reacting to opposing views about the contest, she remarked that, "the Muslims thought it was immoral to bring 92 women to Nigeria and ask them to revel in vanity. What would Muhammad think? In all honesty, he would probably have chosen a wife from one of them.”

This publication triggered violent religious riots that left more than 200 dead and 1000 injured, while 11,000 people were rendered homeless. Ten days after, an Islamist government of Zamfara State, issued a fatwa against Isioma Daniel. This publication, undoubtedly generated ripples that unsettled the country.

Similarly, a serious sectarian violence was sparked in 2006 following cartoons first printed in September by a Danish newspaper and reprinted in European media and later other countries.

The caricatures which angered some Muslim extremist saw some youths in Nigerian northern city of Potiskum armed with machetes and clubs, attacking shops belonging mostly to Christians and burning five churches. The violence reportedly followed a weekend protest over the publication in Europe of controversial cartoons of the Muslim Prophet Muhammad that enraged Muslims worldwide. The killings and destruction of property was fully reported in both the print and electronic media.

These reports disclosed the killings of some southerners in the northern part of Nigeria and triggered the retaliation of the southerners. It was reported that about 127 people were killed at the north while 80 died in the south-eastern city of Onitsha. An eye witness (a journalist), had told this researcher that while some of the northerners in Onitsha were burnt to ashes, brutalised, and slaughtered, others ran into the River Niger and those who could swim survived while others drowned.

It would be recalled that the incident made the Hausa community in Onitsha to shift their base and market to its present location at Asaba, Delta State. 
It could rightly or wrongly be said that the news of the killings and destruction of property in the north would not have been heard in the southern part of the country and the multiple killings would have been averted. To this effect, some proponents of the conflict management have suggested that the mass media should suppress or under report some issues which are likely to generate ripples in parts of the country. That is, the media should, for public good, suppress some facts as well as keeping blind eyes to others (subjective/emotional reasoning). It is unarguable that a media report of, "300 Nigerians or southerners killed in any part of Nigeria” would trigger the wrath and retaliation that could lead to war. This explains why some conflict management scholars advocate a play down on such reports by adopting the framing theory by framing the story in a manner that would not incite the public or generate further crisis. The use of number, especially when very large, is also discouraged by conflict management experts.

However, Baran and Davis (2009) state that framing theory challenges a long accepted and cherished tenet of journalists - the notion that news stories can or should be objective. Overtime, some scholars have shifted grounds to argue that objectivity is not realisable in journalism as man is naturally subjective due to his emotions. These scholars also argue that news angle and dictions are subjected to the writer hence the impossibility of objectivity. This dominating subjective position which the media have assume informs (YII \& Parajon, 2007), to note that media, and the way in which they select material to report, are simply not a reliable catalyst for policy change and that the international community would do well to recognise the danger of calibrating its responses to the substance and timing of the information it receives from the media reports.

It should be stated here that proponents of the above argument of subjectivity probably do not have a full understanding of the objectivity concept and tenets. This explains why Dominick (2011), stressed that Objectivity simply means that the reporter tries to transmit the news untainted by conscious bias and without personal comment or coloration.

Although Dominick agrees that complete and total objectivity is not possible because the process of reporting itself requires countless judgement, each influenced in some way by the reporters value system, but he emphasised that journalists have traditionally respected the truth, refused to distort facts deliberately, and consciously detached themselves as much as possible from what they were reporting. Similarly, C.P. Scott, a famous editor of Guardian (Britain) stressed on factual reporting in compliance with the objectivity principle. To celebrate the centenary of the Guardian and his $50^{\text {th }}$ anniversary as editor, C. P. Scott wrote “A Hundred Years" in 1921. The essay's famous sentence "comment is free, but facts are sacred" has endured as the ultimate statement of value for a free press and continues to underpin the traditions of the Guardian newspaper today.

Therefore, journalists as well as newspaper or media organisations should endeavour to separate facts from comments as the objectivity tenet entails facts, accuracy, truth, and balance. In the words of Hasan (2013), journalists who hold unto objectivity should endeavour to separate facts from opinion, while also treating opinion as relevant.

In whole, YII and Parajon (2007) summarised the role of the media in conflict management into three by saying that that:

- International media have the potential to influence governments and international organisations, and as such can have an agenda-setting effect. These reports, however, are not always the most accurate reflection of the relative severity and risk of a particular conflict.

- Donors that are interested in conflict prevention and sustaining stability should support local media. Local media often yield non-tangible results in war-torn communities, such as increased levels of trust, increase hope in the future of the country, and the ability to contribute to a peaceful society.

- Guarantees regarding the media and freedom of the press-as well as efforts to promote professional, objective, unbiased reporting — should be an integral part of any successful peace agreement.

\section{Methods}

This study employs the documentary or historical survey method in the collection of data. This is a method where data are collected through books, journals, documents and the internet.

\section{Discussion of Findings}

Here, the researchers answered the questions raised in the study by discussing the findings gathered in the course of the study. The questions are analysed sequentially. 


\subsection{Is There Media Objectivity?}

Using the method stated above, it was discovered that there is longstanding and cherished principle of media objectivity which still forms the bases of good journalism practice. Although some scholars and practitioners tend to ignore it, that does not undermine its existence or its inevitability in good and professional practice of journalism.

\subsection{How Do the Media Manage Conflict?}

Media are naturally attracted to conflict because conflict situations provide the media with a ready source of raw materials used by them for the production of news stories and documentaries for their target audience, (Udomisor, 2013). Put differently, Botes (1996) cited in Udomisor (2013) notes that conflict is the bread and butter of journalism because it is the source of sensation, which sells for the media. This probably explains why the mass media blow seemingly innocuous event and issues out of proportion thereby precipitating and igniting crisis all in an effort to make commercial success of their publication or station. There are criticism that the mass media are sometimes used to fight individuals or group battle by rich and powerful people, and the sometimes mislead public through hasty publication due to inadequate research and impatience.

In attempt to spell out the roles of the media in conflict situation, Botes presents five posers which are:

1) How should those involved in public communication respond to potential and actual conflict?

2) What roles should journalist play in covering conflict?

3) Should professional journalist merely report, comment on or interpret conflict or should they be actors in the resolution and particularly the prevention of conflict?

4) What are the moral and social responsibilities of journalists involved in reporting conflict situations?

5) Should a journalist who covers conflict play a role in their mediation and resolution?

In an effort to resolve these posers, Cousins (1996) in Udomisor (2013) explains that we have problem in distinguishing what is management problem from dispute and conflict, and it is equally very problematic in separating problem of competing interests from problem deeply rooted in the questions of culture and identity that may be at stake.

The media have over the years involved in the management of conflict due to the central role which they play in the socio-economic development of every society. They have however, employed different ways of carrying out this task including but not limited to:

a) Framing: this involves the controlling or shaping of news in a pattern that will not incite others into expanded or multiple conflicts. This is sometimes achieved through either a play down on certain information, choice of words or a slant toward a safe ground that will neither aggravate nor incite conflicting parties into crises or war.

b) Provision of platform through which various options are considered for the resolution of conflict.

\subsection{How Can the Media Manage Conflict in the Face of Objectivity Principle?}

While it is expected that the mass media should be involved in conflict management, their efforts or attempt to manage conflict should not negate the long standing and cherished principle of journalism—objectivity. This can be achieved through the following ways:

1) Proactive conflict management: in recent past, some conflict management experts have observed with dismay that organisations pay less attention to potential conflict situations but relaxed till the conflict snowballed into crisis. Proactive management approach entails the act of carefully thinking ahead as well as employing all necessary strategies to ensure that all potential conflict situation and impending conflict are nipped in the bud. This has been seen as the best approach to all forms or types of management, though it might not always be successful but it gives no scar to an organisation and the organisation continues to luxuriate in an enviable reputation.

2) Investigative journalism: As earlier state, most conflicts are as a result of a lack of effective communication, lack of vital and accurate information as well as a breach in communication. These therefore, make investigative journalism a very important part of effective conflict management. Hasan (2013: p. 235) notes that investigative journalism is a kind of journalism in which reporters deeply investigate a topic of interest, often involving crime, political corruption, or some other scandal. "investigative and interpretative reporting is not nec- 
essarily getting 'scoops' and sensationalising them but rather 'situation reporting' in place of event or personality reporting.”

3) Peace journalism: This is activist news writing engaged to promote peace. In practice, peace journalism is a linguistic and action orientation that frames stories to encourage conflict analysis and a non-violent response. It pursues these goals-focusing on conflict resolution, complex truths, non-elite actors affected by war, and potential solutions. A Norwegian Sociologist, Galtung Johan reportedly proposed the idea of peace journalism for journalists to follow when covering war and conflict. Galtung stressed that Peace journalism is contrary to a typical war journalism that focuses on violence, propaganda, elite actors, and victory, emphasising the current conflict while ignoring the causes or outcomes.

4) Gate keeping: One important characteristic of the mass media organisation is the presence of gatekeepers. The gatekeepers control the nature and content of information that gets to the public domain. Hasan (2013) observes that the enormous scope of mass communication demands some control over the selection and editing of the messages that are constantly transmitted to the mass audience. Whether done by individuals or organisations, gate keeping involves setting certain standards and limitations that serve as guidelines for both content development and delivery of a mass communication message. An effective gate keeping would have guarded against the religious riots that resulted from Isioma's comment as well as that of the Danish cartoon.

5) Enlightenment: This is another important approach to a good conflict management. The media can engage in enlightenment programmes or publications that will highlight the interest of each of the conflicting parties. This approach gets the public informed on the danger of conflict, the impact or number of lives which the conflict had caused and the need for the parties to come to a negotiation table.

6) Agenda setting: This is where the mass media wield lots of influence on the public. Whether through investigation, proactive management strategy, gate keeping, peace journalism or enlightenment, the media has the ability to shape the public opinion hence they should seize this opportunity to manage conflict in the society. This can be achieved through news stories, features and opinion articles, editorials, comments and cartons as well as other publications and programmes as pertains to the different types of the media.

\section{Conclusion}

This study has taken a look at media objectivity, conflict and conflict management as well as the role of the media in conflict management. It also reviewed some conflict situations that occurred in Nigeria in 2002 and in 2006, looking at the causes, the role played by the media and how they would have been avoided through an effective gate keeping function. It was found that the media are naturally attracted to conflict and some journalists/ media organisations use their position to fight individual or group battle while others blow some seemingly innocuous issues out of proportion thereby generating conflict in the society. It was also noted that the media sometimes play down, frame or slant some facts to avoid escalation of conflict but these negate the principle of objectivity. Media practices which undermine the ethical principles of journalism—objectivity—were analysed and better approaches to conflict management which does not negate the ethical code advocated. This study submits that the media can better manage conflict without breaching the cherished tenet of journalism through gate keeping, peace journalism, investigative journalism, and proactive conflict management approaches among others.

\section{Recommendations}

Conflict management has recently become an integral part of mass communication organisations owing to their centrality in the society. While it is imperative for the media to involve in conflict management, the longstanding and cherished principle of journalism—objectivity—must not be negated. It is therefore recommended that the media can involve in conflict management through numerous ways including:

- Investigative journalism,

- Peace journalism,

- Proactive conflict management approach,

- Gate keeping,

- Agenda setting for peaceful co-existence,

- Enlightenment of conflicting parties on the intricacies of the conflict in question.

- A journalist or/and media organisation should completely avoid a story which he is not independent of. That 
is a story which his interest is involved either directly or indirectly.

- In all, objective and responsible journalism should not be sacrifice at the altar of scoops to make good and sensational headlines that would sell the paper or station.

- The media should at all times value, uphold and apply objectivity in all its reportage, by separating facts from comments, for effective conflict management. The media should also embrace proactive conflict management approach, peace journalism, investigative journalism and agenda setting for peaceful resolution of conflicts.

\section{References}

Akpan, N. (2005). Conflicts in Nigeria’s Niger Delta: Issues on Response and Management. International Journal of Social Sciences, 4, 161-175.

Baran, S. J. (2004). Introduction to Mass Communication; Media Literacy and Culture. New York, NY: McGraw-Hillin.

Baran, S., \& Davis, D. (2009). Mass Communication Theory: Foundation, Ferment, and Future (5th ed.). Boston, MA: Wadsworth Cengage Learning.

Dominick, J. (2011). The Dynamics of Mass Communication. Media in Transition (11th ed.). New York, NY: McGraw Hill.

Elliot, A., Timothy, W., \& Robin, A. (2004). Media \& Research Update: Social Psychology. Upper Saddle River, NJ: Pearson Education Inc.

Hasan, S. (2013). Mass Communication: Principles and Concepts (2nd ed.). New Delhi, Delhi: CBS Publishers \& Distributors Pvt Ltd.

Ibrahim, G. (2002). Conflict in Democracies. In U. A. Pate (Ed.), Introduction to Conflict Reporting in Nigeria (pp. 18-29). Lagos: Frankad Publishers.

McQuail, D. (2005). Mass Communication Theory. London: Sage Publications.

Ofor, C. (2004). Nigerian Press: Review, Trends and Prospects. Port-Harcourt, Rivers State: Penpower Communications.

Owens-Ibie, N. (2002). Socio-Cultural Considerations in Conflict Reporting in Nigeria. In U. A. Pate (Ed.), Introduction to Conflict Reporting in Nnigeria (pp. 30-44). Lagos: Frankad Publishers.

Udomisor, I. (2002). Problems and Prospects of Reporting Conflict in a Democracy: The Editors Challenge. In U. A. Pate (Ed.), Introduction to Conflict Reporting in Nnigeria (pp. 84-98). Lagos: Frankad Publishers.

Udomisor, I. (2013). Media as a Party in Conflict, Conflict Management and Resolution: The Case of South Africa. International Journal of Management Sciences, 1, 245-253.

YII, B., \& Parajon, C. (2007). The Role of the Media in Conflict. Washington DC. http://www.youtube.com/user/usinstituteofpeace 